\title{
POTENCIAL DE ISOLADOS DE Bacillus sp. PARA O CONTROLE DE Curtobacterium flaccumfaciens pv. flaccumfaciens
}

\author{
Lucas Antônio Rocha ${ }^{1}$, Bruno Sérgio Vieira ${ }^{2}$, Lara Caroline Borges Moreira Mota ${ }^{3}$, Everaldo Antônio Lopes ${ }^{4}$
}

\author{
${ }^{1}$ Engenheiro Agrônomo. Centro Universitário de Patos de Minas (Unipam). \\ ${ }^{2}$ Engenheiro Agrônomo, Doutor em Fitopatologia. Instituto de Ciências Agrárias, Universidade Federal de Uberlândia, Campus Monte \\ Carmelo, Rodovia LMG 746, Km 01, s/n, Bloco 1. Monte Carmelo-MG, Brasil. CEP: 38500-000. \\ ${ }^{3}$ Engenheira Agrônoma. Instituto de Ciências Agrárias, Universidade Federal de Uberlândia, Campus Umuarama.. \\ ${ }^{4}$ Engenheiro-Agrônomo, Doutor em Fitopatologia. Universidade Federal de Viçosa - Campus de Rio Paranaíba. Rodovia MG 230, Km \\ 07, Caixa Postal 22, Campus II UFV. Rio Paranaíba - Minas Gerais. CEP: 38810-000.
}

*Autor para correspondência: Bruno Sérgio Vieira, brunovieira@ufu.br

\begin{abstract}
RESUMO: A murcha-de-curtobacterium, doença causada pela bactéria Curtobacterium flaccumfaciens pv. flaccumfaciens (Cff), tem causado prejuízos na cultura do feijoeiro (Phaseolus vulgaris L.) na região do Alto Paranaíba (MG). Este trabalho teve como objetivo avaliar o efeito da microbiolização de sementes de feijoeiro com dez isolados de Bacillus sp. em condições de casa de vegetação. $O$ tratamento de sementes com os todos os isolados, exceto o 4 e 8, reduziu a severidade da doença em comparação com a testemunha inoculada com Cff, especialmente os isolados 1, 6, 7 e 10. A altura de plantas foi maior após o tratamento de sementes com o isolado 6 em comparação com a testemunha inoculada. Por outro lado, a microbiolização com nenhum dos isolados bacterianos testados aumentou a biomassa das raízes e da parte aérea das plantas em comparação com plantas não tratadas e inoculadas com Cff. Novos estudos devem ser conduzidos em campo para confirmar o potencial dos isolados 1, 6, 7 e 10 no manejo da doença.
\end{abstract}

PALAVRAS-CHAVES: Murcha-de-Curtobacterium, feijoeiro, biocontrole, antagonismo.

\section{POTENTIAL OF Bacillus sp. ISOLATES TO THE CONTROL OF Curtobacterium flaccumfaciens pv. flaccumfaciens}

\begin{abstract}
The Curtobacterium wilt, disease caused by the bacterium Curtobacterium flaccumfaciens pv. flaccumfaciens (Cff), has caused losses on bean (Phaseolus vulgaris L.) in the Alto Paranaíba (MG). This work aimed to evaluate the effect of the bean seed microbiolization with ten Bacillus sp. isolates under greenhouse conditions. Seeds treatment with all the isolates, except the 4 and 8 , reduced the severity of the disease in comparison to the Cff-inoculated control, particularly the isolates 1,6,7 and 10. The height of the plants was higher after the treatment with the isolate 6 in comparison to the infested control. On the hand, the microbiolization with none of tested bacterial isolates influenced the root and shoot biomasses when compared to the infested control. Further studies should be carried out under field conditions in order to confirm the potential of the isolates 1, 6, 7 and 10 on the management of the disease.
\end{abstract}

KEY-WORDS: Curtobacterium wilt, bean, biocontrol, antagonist.

\section{INTRODUÇÃO}

O feijão (Phaseolus vulgaris L.) é uma das espécies agrícolas de maior importância econômica e social no Brasil, por ser cultivado em grandes áreas e pela mão-de-obra empregada durante o ciclo da cultura (Carbonell e Pompeu, 2000). O Brasil é o maior produtor mundial dessa leguminosa, com destaque para os estados do Paraná, Minas Gerais, São Paulo e Goiás, com inúmeras lavouras irrigadas e altas produtividades médias (Conab, 2016).

No entanto, um dos principais fatores que limitam a produtividade da cultura no Brasil e em todo o mundo é a ocorrência de doenças. No feijoeiro, mais de $50 \%$ das suas principais doenças têm seus agentes causais transmitidos via sementes (Freitas, 2007). Assim, severas epidemias das doenças no campo 
podem ocorrer caso exista a transmissão do patógeno para a plântula originada de semente contaminada (Estefani et al., 2007). No caso do feijoeiro, a tradição do uso de sementes próprias favorece que tais eventos indesejáveis ocorram no campo, sendo um dos principais entraves ao incremento da produtividade da cultura (Estefani et al., 2007).

A cultura do feijoeiro é afetada por vários tipos de patógenos causadores de doenças, as quais podem ser de origem fúngica, virótica e bacteriana que acarretam perdas significativas na produção (Estefani et al., 2007). Dentre os principais patógenos bacterianos que ocorrem em várias localidades do mundo inclui-se a bactéria Curtobacterium flaccumfaciens pv. flaccumfaciens (Hedges) Collins e Jones (Cff), causadora da murcha-de-Curtobacterium Saettler (Sammer e Reiher 2012; Soares et al. 2013; Urrea e Harveson 2014; Osdaghi, 2015). A constatação de C. flaccumfaciens pv. flaccumfaciens (Cff) somente foi relatada no Brasil, em 1995 no Estado de São Paulo (Maringoni e Rosa, 1997), e hoje se encontra distribuída em varias regiões produtoras de feijão principalmente nas regiões Sul e Sudeste (Valentini et al., 2011). Recentemente a enfermidade tem sido observada na região do Alto Paranaíba, em Minas Gerais, o que vem causando preocupação aos produtores de feijão, em razão da agressividade do patógeno e da dificuldade de manejo da doença.

A bactéria causadora da murcha-deCurtobacterium é um parasita vascular que infecta as plantas a partir de sementes, ferimentos ou aberturas naturais, podendo sobreviver em restos de cultura, no solo e em sementes (Estefani et al., 2007; Miranda Filho, 2010). Os sintomas típicos da doença em feijoeiro são principalmente murcha, escurecimento vascular $\mathrm{e}$ morte da parte aérea (Miranda Filho, 2010).

O controle químico para essa doença não é eficiente e comumente são utilizados produtos a base de cobre para o controle de doenças bacterianas. Os produtos tem ação fungicida, e atuam, também, em bactérias com ação bacteriostática, porém aplicações foliares na tentativa de controle da murcha-deCurtobacterium, onde o patógeno coloniza os vasos do xilema, não conseguem um contato direto do produto com o patógeno. $\mathrm{O}$ uso de sementes de boa qualidade, emprego de cultivares resistentes e a rotação de culturas podem contribuir para redução da doença (Miranda Filho, 2010).
Considerando a busca por alternativas de manejo desta doença, o tratamento de sementes de feijoeiro com agentes de biocontrole, a exemplo de Bacillus spp. Cohn, pode ser uma ferramenta importante a ser adotada no manejo integrado da murcha-deCurtobacterium (Rocha et al., 2009).

Desta forma, o objetivo deste trabalho foi avaliar o potencial de dez isolados de Bacillus sp., aplicados na forma de microbiolização das sementes, sobre a murcha-de-Curtobacterium em feijoeiro sob condições de casa de vegetação.

\section{MATERIAL E MÉTODOS}

O trabalho foi realizado no Laboratório de Microbiologia e Fitopatologia e na casa de vegetação pertencente ao referido laboratório, ambos situados no Bloco H do Centro Universitário de Patos de Minas (UNIPAM), no período de 01 de julho a 01 de novembro de 2011.

Os isolados de Bacillus sp. e de Cff utilizados no trabalho pertencem ao acervo microbiológico dos Laboratórios de Genética (GENEB) e de Microbiologia e Fitopatologia do Bloco H do do Unipam, respectivamente.

$\mathrm{Na}$ realização do ensaio, 0 isolado de Cff foi repicado para o meio de cultura 523 (Kado e Heskett, 1970) pelo método de estrias e incubado a $28{ }^{\circ} \mathrm{C}$, por $48 \mathrm{~h}$. Em seguida, as células foram colhidas da superfície do meio através de raspagem e transferidas para meio 523 líquido e cultivado por 24h em agitador orbital a 150 rpm a $28^{\circ} \mathrm{C}$. Após o período de incubação, $100 \mu \mathrm{L}$ da suspensão bacteriana foram plaqueados em placas de Petri de $9 \mathrm{~cm}$ de diâmetro, contendo $20 \mathrm{~mL}$ do meio de cultura CNS acrescido de manitol (Behlau et al., 2006), espalhados com alça de Drigalski estéril e incubados por $48 \mathrm{~h}$ a $28^{\circ} \mathrm{C}$. Em seguida, as sementes foram inoculadas em condições assépticas. Para tal, 50 sementes de feijão (cv. Carioca) foram mantidas em BOD por 24 horas a $28^{\circ} \mathrm{C}$ em contato com a cultura de Cff em placa de Petri contendo meio CNS e manitol.

Os isolados de Bacillus sp. foram previamente cultivados em meio de cultura 523 por 24 horas. Após esse período, foram preparadas suspensões com solução salina $(\mathrm{NaCl} 0,85 \%)$ para cada um dos isolados em concentrações ajustadas para 1,0 $x 10^{9}$ ufc $\mathrm{mL}-1$. Posteriormente, sementes de feijão cv. Carioca previamente infectadas com Cff foram 
imersas em solução salina contendo cada isolado de Bacillus sp. e submetidas à agitação por 5 horas a temperatura de $10^{\circ} \mathrm{C}$. As testemunhas foram caracterizadas por sementes inoculadas imersas em solução salina e sementes sem nenhum tratamento. Após a microbiolização, três sementes foram distribuídas por vaso de $300 \mathrm{~mL}$, contendo substrato de fibra de coco esterilizado. Após a emergência das plantas foi realizado o desbaste, deixando apenas uma planta por vaso.

Aos 20 dias após o semeio, foram avaliadas a altura e a biomassa de raízes e da parte aérea das plantas, além da severidade da murcha-deCurtobacterium, que foi realizada com o uso da escala descritiva de Schoonhoven e Pastor-Corrales (1987) (Tabela 1), adaptada por Maringoni (2002).

Tabela 1. Escala de notas descritivas de severidade de Fusarium oxysporum f. sp. phaseoli de Schoonhoven e Pastor-Corrales (1987) e adaptada para a avaliação da murcha-de-Curtobacterium (Curtobacterium flaccumfaciens pv. flaccumfaciens) (Maringoni, 2002).

\begin{tabular}{cl}
\hline Nota & \\
\hline 1 & Sem sintomas \\
3 & Menos de $10 \%$ de folhas murchas \\
5 & $25 \%$ de folhas apresentam murcha e amarelecimento \\
7 & Aproximadamente $50 \%$ de folhas murchas, amarelecidas e necrosadas. \\
9 & $\begin{array}{l}\text { Aproximadamente } 75 \% \text { ou mais de folhas murchas, nanismo severo, necroses, desfolha prematura e morte precoce da } \\
\text { planta. }\end{array}$ \\
\hline
\end{tabular}

O delineamento experimental adotado foi do tipo inteiramente casualizado (DIC), composto de 12 tratamentos (sementes inoculadas com Cff e tratadas com 10 isolados de Bacillus sp., testemunha não tratada e inoculada com Cff e testemunha não tratada e não inoculada com a fitobactéria), com 12 repetições por tratamento e cada repetição constituída por um vaso contendo uma planta.

Os dados de altura e massa das plantas foram submetidos à análise de variância $(p<0,05)$ e as médias dos tratamentos foram comparadas entre si pelo teste de Tukey $(p<0,05)$; enquanto que os dados de severidade foram analisados pelo teste de Kruskal-Wallis $(p<0,05)$. As análises foram feitas usando o pacote estatístico Statistica 7.0 (Statsoft, 2004).

\section{RESULTADOS E DISCUSSÃO}

0 tratamento de sementes de feijoeiro com todos isolados, exceto 04 e 08 , reduziu a severidade da murcha-de-Curtobacterium em comparação com a testemunha inoculada com o patógeno (Figura 1A). A microbiolização das sementes de feijão com os isolados 1, 6, 7 e 10 reduziram em 85, 57, 61 e $69 \%$ a severidade da murcha-de-Curtobacterium, respectivamente.
Em relação à altura de plantas, o maior desenvolvimento das plantas foi observado em plantas não inoculadas com Cff, não diferindo dos tratamentos envolvendo os isolados 1, 2, 6, 7 e 10 (Figura 1B). Dentre esses, plantas tratadas apenas com 0 isolado 6 tiveram maior altura média em comparação com a testemunha inoculada com Cff. Plantas não inoculadas com a bactéria patogênica tiveram maior acúmulo de massa fresca da parte aérea e das raízes. Embora alguns isolados não tenham diferido estatisticamente dessa testemunha, tais isolados não diferiram da testemunha inoculada (Figura 1C). A redução do crescimento da parte aérea e das raízes do feijoeiro em plantas infectadas por Cff ocorre em função da degradação das paredes dos vasos de xilema em decorrência da colonização do patógeno, dificultando o transporte de água e nutrientes (Miranda Filho, 2010).

O gênero Bacillus é reconhecido pelo potencial de biocontrole de diferentes doenças para diversas espécies vegetais, incluindo o feijoeiro (Melo e Azevedo, 2000). Assim como no presente trabalho, Rocha et al. (2009) observaram que a microbiolização de sementes de feijoeiro com $B$. cereus e Bacillus sp. é uma técnica promissora para o manejo de Cff. 
Figura 1. Severidade da murcha-de-Curtobacterium (A), altura de plantas (B) e massa da parte aérea e de raízes $(C)$ de feijoeiros cv. Carioca originados de sementes inoculadas com Curtobacterium flaccumfaciens pv. flaccumfaciens (Cff) e tratadas com diferentes isolados de Bacillus sp. Médias seguidas pela mesma letra na coluna não diferem entre si $(p<0,05)$ pelos testes de Kruskal-Wallis $(A)$ ou Tukey (B e C). T1 = Testemunha não tratada com Bacillus e não inoculada com Cff. T2 = Testemunha não tratada com Bacillus e inoculada com Cff. I-1 a $\mathrm{I}-10=$ Isolados de Bacillus sp. CV(\%)=28,16 (Severidade); 12,03 (Altura); 18,92 (Massa da parte aérea); 17,20 (Massa das raízes). Dados transformados para $\sqrt{x}$ antes das análises. Médias originais apresentadas.

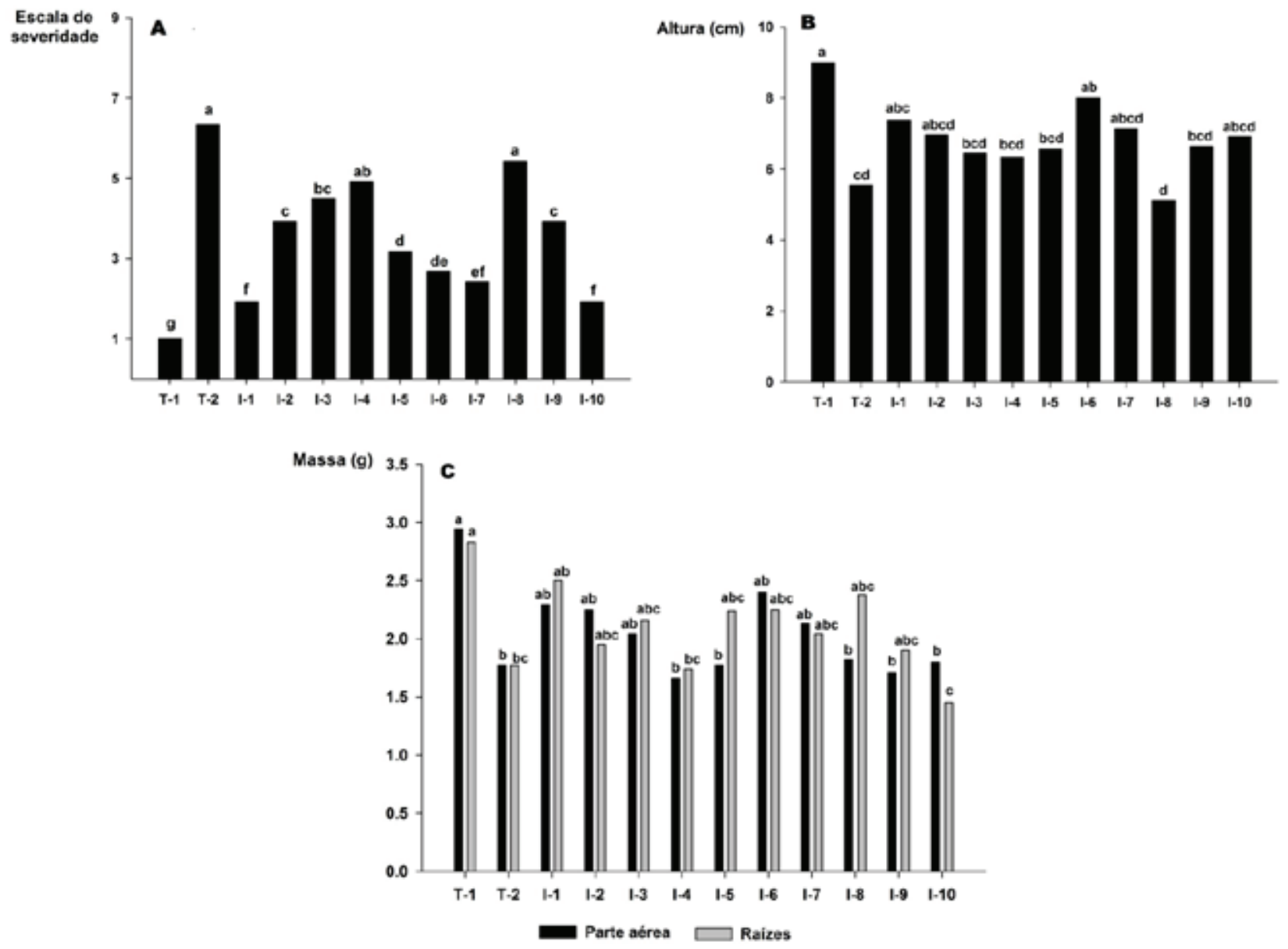

O controle de patógenos por bactérias antagonistas, a exemplo de Bacillus, pode ocorrer em decorrência de diversos mecanismos de ação, como a antibiose, o parasitismo, a competição e a indução de resistência (Mariano et al., 2004; Santos, 2004; Lanna et al., 2010). No caso de Bacillus, a produção de endósporos é uma vantagem, pois aumenta a sua sobrevivência e a vida de prateleira de bioprodutos (Oliveira et al., 2006).

0 tratamento de sementes com antagonistas pode eliminar, impedir ou reduzir o desenvolvimento de patógenos transportados pela semente ou presentes no solo (Menten, 1996). O uso de tratamento de sementes com espécies de Bacillus se mostrou eficiente na redução de várias doenças, como a mancha-aquosa em melão, incitada por Acidovorax avenae subsp. citrulli (Medeiros et al., 2003; Santos, 2004; Oliveira et al., 2006) e a podridão-negra das crucíferas, causada por Xanthomonas campestris pv. campestris (Pammel) Dowson (Assis et al., 1995; 1996; 1997). No caso da mancha-aquosa, o tratamento de sementes infectadas com o patógeno com líquidos fermentados com ou sem presença das células de $B$. subtilis R14, $B$. megaterium pv. cerealis RAB7, B. pumilis C116, Bacillus sp. MEN2 controlou a doença, possivelmente em razão de compostos bioativos produzidos por Bacillus, parcialmente caracterizados como lipopeptídeos (Santos, 2004). No patossistema Xanthomonas-couve, o isolado de R14 de $B$. subtilis reduziu em $100 \%$ a doença em plantas tratadas (Assis et al., 1996); enquanto que os isolados C210 (B. cereus), C116 (B. megaterium), R14 (B. 
subtilis) e C240 (B. cereus) reduziram a severidade da doença em $78,74,73$ e $71 \%$, respectivamente, em condições de campo (Assis et al., 1997). Lipopeptídeos produzidos por Bacillus possivelmente são os principais envolvidos na supressão do patógeno em cruciferas (Monteiro, 2003).

Na prática, poucos micro-organismos exercem um único mecanismo antagônico, bem como os mecanismos não são mutuamente exclusivos, uma vez que sua importância relativa pode ser variável com as condições ambientais, estádio de desenvolvimento do agente biocontrolador e do fitopatógeno (Andrews, 1992). No presente trabalho, observou-se o potencial de biocontrole de $C$. flaccumfaciens pv. flaccumfaciens por meio da microbiolização de sementes de feijoeiro com os isolados de Bacillus sp., principalmente os isolados 1, 6, 7 e 10. Necessita-se, pelo exposto, de novos estudos com estes isolados a fim de elucidar mecanismos de ação envolvidos no antagonismo (Dev Sharma et al., 2013) e de experimentação em condições de campo para confirmar o potencial dos isolados.

\section{REFERÊNCIAS BIBLIOGRÁFICAS}

Andrews, J. H. Biological control in the phyllosphere. Annual Review of Phytopathology. 1992, 30, 603-635.

Assis, S.M.P.; Mariano, R.L.R.; Michereff, S.J.; Silva, G.; Maranhão, E.A.A. Antagonism of Bacillus spp. to Xanthomonas campestris pv. campestris on cabbage phylloplane in field. Anais of $40^{\circ}$ International Workshop on Plant Growth-Promoting Rhizobacteria, Sapporo, Japan. 1997, 345-348.

Assis, S.M.P.; Mariano, R.L.R.; Reis, A.; Silveira, E.B.; Michereff, S.J. Ação de rizobactérias no crescimento de rabanete e no controle biológico da podridão negra e da antracnose. Arquivos de biologia e tecnologia, 1995, $38,843-850$.

Assis, S.M.P.; Mariano, R.L.R.; Michereff, S.J.; Coelho, R.S.B. Biocontrol of Xanthomonas campestris pv. campestris on kale with Bacillus spp. and endophytic bacteria. In. Advances in Biological control of Plant Diseases. Edição no. 2; Wenhua, T., Cook, R.J. \& Rovira, Eds.; China Agricultural University Press: Beijing, China, 1996, 347-353.
Behlau, F.; Nunes, L.M.; Leite Jr.; R.P. Semi-selective medium for detection of Curtobacterium flaccumfaciens pv. flaccumfaciens in soil and on bean seeds. Summa Phytopathologica, 2006, 32, 394-396.

Carbonell, S.A.M; Pompeu, A.S. Estabilidade fenotípica de linhagens de feijoeiro em três épocas de plantio no estado de São Paulo. Pesquisa Agropecuária Brasileira, 2000, 35, 2, 321-329.

Conab - Companhia Nacional de Abastecimento. Disponível em: http://www.conab.gov.br/. Acesso em 04 de abril de 2016.

Dev Sharma, S.C.; Shovon, M.S.; Jahan, M.G.S; Asaduzzaman, A.K.M.; Rahaman, M.A.; Biswas, K.K.; Abe, N.R. Antibacterial and cytotoxic activity of Bacillus methylotrophicus-scs 2012 isolated from soil. Journal of Microbiology, Biotechnology and Food Sciences. 2013, 2, 2293-2307.

Estefani, R.C.C.; Miranda Filho, R.J.; Uesugi, C.H. Tratamentos térmico e químico de sementes de feijoeiro: eficiência na erradicação de Curtobacterium flaccumfaciens pv. flaccumfaciens e efeitos na qualidade fisiológica das sementes. Fitopatologia Brasileira, 2007, 32, 5, 434-438.

Freitas, R.A. Patologia de sementes de feijão. http:// www.patologiadesementes.com.br. Acesso: 22 Jun. 2007.

Kado, C. J.; Heskett, M.G. Selective media for isolation of Agrobacterium, Corynebacterium, Erwinia, Pseudomonas and Xanthomonas. Phytopathology, 1970, 60, 969-976.

Lanna, F.R.; Ferro, H.M.; Pinho, R.S.C. Controle biológico mediado por Bacillus subtilis. Revista Trópica - Ciências Agrárias e Biológicas, 2010, 4, 1220.

Mariano, R.L.R.; Silveira, E.B.; Assis, S.M.P.; Gomes, A.M.A.; Nascimento, A.R.; Donato, V.M.T.S. Importância de bactérias promotoras de crescimento e de biocontrole de doenças de plantas para uma agricultura sustentável. Academia Pernambucana de Ciência Agronômica, 2004, 1, 89-111. 
Maringoni, A.C. Comportamento de cultivares de feijoeiro comum à murcha-de-Curtobacterium. Fitopatologia Brasileira, 2002, 27, 2, 157-162.

Maringoni, A.C.; Rosa, E.F. Ocorrência de Curtobacterium flaccumfaciens pv. flaccumfaciens em feijoeiro no Estado de São Paulo. Summa Phytopathologica, 1997, 23, 160-162.

Medeiros, F.H.V.; Silva Neto, E.B.; Mariano, R.L.R.; Viana, I.O. Proteção de plantas de melão contra Acidovorax avenae subsp. citrulli mediada por Bacillus spp. Fitopatologia Brasileira, 2003, 368. (Resumo).

Melo, I.S.; Azevedo, J.L. Controle Biológico. Embrapa Meio Ambiente, Jaguariúna: Embrapa Meio Ambiente, 2000, 2, 388 p.

Menten, J.O.M. Tratamento de sementes. In: Anais of Simpósio brasileiro de patologia de sementes, 4., 1996, Gramado, RS. 3-23.

Miranda Filho, R.J. Etiologia, Epidemiologia e fisiologia da murcha de curtobacterium. 2010. 116 f. Dissertação (Doutorado em Fitopatologia) - Universidade de Brasília.

Monteiro, L., Mariano, R.L.R.; Souto-Maior, A.M. Production of active compounds against Xanthomonas campestris pv. campestris by Bacillus species. In: Anais of XIV Simpósio Nacional De Fermentações, Florianópolis, SC. 2003. CD Rom.

Osdaghi, E.; Sardrood, B.P.; Bavi, M.; Oghaz, N.A.; Hadian, S.K.A. First Report of Curtobacterium flaccumfaciens pv. flaccumfaciens causing cowpea bacterial wilt in Iran. Journal of Phytopathology, 2015, 16, 653-656.

Oliveira, A.; Santos, M.H.M.; Silveira, E.B.; Gomes, A.M.A.; Mariano, R.L.R. Biocontrole da mancha-aquosa do melão pelo tratamento de sementes com bactérias epifíticas e endofíticas. Horticultura Brasileira, 2006, 24, 373-377.

Rocha, D.J.A.; Corrêa, B.O.; Buss, R.B.; Moura, A.B. Avaliação do potencial de rizobactérias para o biocontrole de Curtobacterium flaccumfaciens pv. flaccumfaciens agente da murcha bacteriana do feijão.
CIC XI EPOS I Mostra Científica. Disponível em: http:// www.ufpel.tche.br/cic/2009/cd/pdf/CA/CA_01571.pdf. Acesso em 18 de abril de 2016.

Santos, E.R. Controle biológico da mancha- aquosa do melão causada por Acidovorax avenae subsp. citrulli. 2004. 60 f. Dissertação de mestrado em AgronomiaUFPE.

Sammer, U.F.; Reiher, K. Curtobacterium flaccumfaciens pv. flaccumfaciens on Soybean in Germany - A Threat for Farming. Journal of Phytopathology, 2012, 160, 314-316.

Schoonhovem, A.V., Pastor-Corrales, M.A. Sistema Estandár para La Evaluación de Germoplasma de Frijol. p.42. Centro Internacional de Agricultura. Cali, Colômbia. 1987. Disponível em: http://books.google. com/books?id=mpglE jDedMC. Acesso em 18 março de 2016.

Soares, R.M.; Fantinato, G.G.P; Darben, L.M.; Marcelino-Guimarães, F.C.; Seixas, C.D.S.; Carneiro, G.E.S. First report of Curtobacterium flaccumfaciens pv. flaccumfaciens on soybean in Brazil. Tropical Plant Pathology, 2013, 38, 452-454.

Statsoft, Inc. 2004. Statistica for windows (Computer program manual). Tulsa, OK. Disponível em: http:// www.statsoft.com.

Urrea, C.A.; Harveson, R.M. Identification of Sources of Bacterial Wilt Resistance in Common Beans (Phaseolus vulgaris L.). Plant Disease, 2014, 98, 973-976.

Valentini, G.; Baldissera, J.N.C.; Morais, P.P.P.; Stähelin, D.; Heidemann, Crescêncio, J.; Stenger, F.; Elias, H.T.; Guidolin, A.F.; Coimbra, J L.M. Herança da resistência em feijoeiro à murcha causada por Curtobacterium flaccumfaciens pv. flaccumfaciens. Pesquisa Agropecuária Brasileira, 2011, 46, 9, 10451052. 